Check for updates

Cite this: Nanoscale Adv., 2019, 1, 4365

\title{
A long-lifespan, flexible zinc-ion secondary battery using a paper-like cathode from single-atomic layer $\mathrm{MnO}_{2}$ nanosheets $\dagger$
}

\author{
Yanan Wang, ${ }^{a}$ Zeyi Wu, ${ }^{a}$ Le Jiang, ${ }^{a}$ Wenchao Tian, ${ }^{a}$ Chenchen Zhang, ${ }^{b}$ Cailing Cai ${ }^{a}$ \\ and Linfeng $\mathrm{Hu}$ (iD *a
}

Aqueous zinc ion secondary batteries (ZIBs) have recently attracted considerable attention and global interest due to their low cost, aqueous-based nature and great safety. Unfortunately, the intrinsic properties of poor cycle life, low energy density and uncontrolled dendrite growth during the charge/ discharge process for metallic $\mathrm{Zn}$ anodes significantly hinder their practical application. In this work, we rationally designed two-dimensional (2D) $\delta-\mathrm{MnO}_{2}$ nanofluidic channels by the ordered restacking of exfoliated $\mathrm{MnO}_{2}$ single atomic layers, which exhibited a high zinc ion transport coefficient $\left(1.93 \times 10^{-14}\right.$ $\mathrm{cm}^{2} \mathrm{~s}^{-1}$ ) owing to their appropriate $d$-spacing and the negative charge of the inner channel walls. More importantly, we found that $\mathrm{Zn}$ dendrite growth was prevented in the as-assembled ZlBs, resulting in superior stability compared with the bulk- $\mathrm{MnO}_{2}$ sample. Our design sheds light on developing highperformance ZIBs from two-dimensional nanofluidic channels, and this strategy might be applicable to the storage of other metal ions $\left(\mathrm{Mg}^{2+}, \mathrm{Ca}^{2+}, \mathrm{Al}^{3+}\right.$, etc. $)$ in next-generation electrochemical energy storage devices.

Received 20th August 2019

Accepted 23rd September 2019

DOI: 10.1039/c9na00519f

rsc.li/nanoscale-advances electrical neutrality at the plated electrode surface, leading to a local space charge and ramified $\mathrm{Zn}$ electro stripping/plating on the screw dislocations of the $\mathrm{Zn}$ surface. ${ }^{13}$ Extensive efforts have been devoted to solving the dendrite growth problem in ZIBs. ${ }^{14,15}$ Typical strategies, such as constructing $\mathrm{Zn}$ anodes with a hierarchical architecture and preparing a composite $\mathrm{Zn}$ anode coating as a thin inert layer to stabilize the $\mathrm{Zn}$ anode, have been developed to suppress dendritic growth in ZIBs. ${ }^{16}$ Most recently, Wang et al. achieved great progress on dendrite-free plating/ stripping of $\mathrm{Zn}$ in a highly concentrated $\mathrm{Zn}(\mathrm{TFSI})_{2}$ electrolyte with a supporting salt of LiTFSI (bis(trifluoromethanesulfonyl) imide). ${ }^{17}$ Nevertheless, either the complicated fabrication process of the inert layer or the high cost of the highly concentrated $\mathrm{Zn}$-ion electrolyte hinders widespread application and industrial production. Thus, it is still highly desirable to design a new strategy to realize dendrite-free ZIBs with excellent reversibility and stability.

Two-dimensional (2D) nanostructures with a single-atomic layer thickness have attracted intensive attention for the development of energy-storage devices because of the emergence of novel physical and chemical properties which are distinct from those of or even absent in their bulk counterparts. ${ }^{18-21}$ In particular, 2D nanostructure units are rather soft and flexible and have been considered ideal building blocks of freestanding, flexible membrane samples as high-performance electrodes. ${ }^{22,23}$ Such freestanding electrodes are completely composed of 2D active materials without any current collectors and polymer binders, leading to a superior performance due to
${ }^{a}$ Department of Materials Science, Fudan University, Shanghai 200433, China. E-mail: linfenghu@fudan.edu.cn

${ }^{b}$ State Grid Anhui Electric Power Institute, Hefei, 230022, China

$\dagger$ Electronic supplementary information (ESI) available: Supplementary tables and figures. See DOI: 10.1039/c9na00519f 
the unique structure and significantly decreased interfacial resistance. ${ }^{24}$ More importantly, such a restacked structure in the freestanding, flexible membrane fabricated from the $2 \mathrm{D}$ building blocks could produce lamellar nano-channels and atomically smooth surfaces for nanofluids such as liquid or quasi solid-state electrolytes. ${ }^{25,26}$ It has been verified that $2 \mathrm{D}$ nanochannels obtained by exfoliation and restacking of layered compounds are ideal frameworks for fast Li-ion storage because of their abundant interconnected (horizontal and vertical) channels, large active surface and short diffusion path. ${ }^{27}$

Most recently, flexible ZIBs based on binder-free $\alpha-\mathrm{MnO}_{2}$ nanosheets/rGO on carbon cloth have been realized. ${ }^{28}$ However, the $\alpha-\mathrm{MnO}_{2}$ nanosheets in this work were synthesized by a hydrothermal route and their thickness is much larger than the single layer thickness. The resulting $\alpha-\mathrm{MnO}_{2}$ nanosheets/ rGO thin-film generally exhibits a rough surface and a loose, overlapping structure with the absence of 2D nanochannel characteristics. We note that the recent advances in layered$\mathrm{MnO}_{2}$ demonstrate that it can be exfoliated into 2D negatively charged nanosheets with single-atomic layer thickness by a softchemical strategy. ${ }^{29,30}$ Is it possible to construct unique $2 \mathrm{D}$ nanochannels with controllable interlayer spacing from these $2 \mathrm{D}$ building blocks? What would happen in these $2 \mathrm{D}$ nanofluidic channels for $\mathrm{Zn}^{2+}$ transport? It would be of great interest to study the performance of ZIBs constructed from such freestanding nanochannels and further understand the $\mathrm{Zn}^{2+}$ storage mechanism.

Inspired by this consideration, herein, we demonstrate a proof-of-concept strategy to construct 2D nanofluidic channels from liquid-exfoliated $\mathrm{MnO}_{2}$ single-layer nanosheets (Fig. 1). The as-constructed paper-like $\mathrm{Zn}$ ion battery from these nanofluidic channels exhibited excellent flexibility and a high
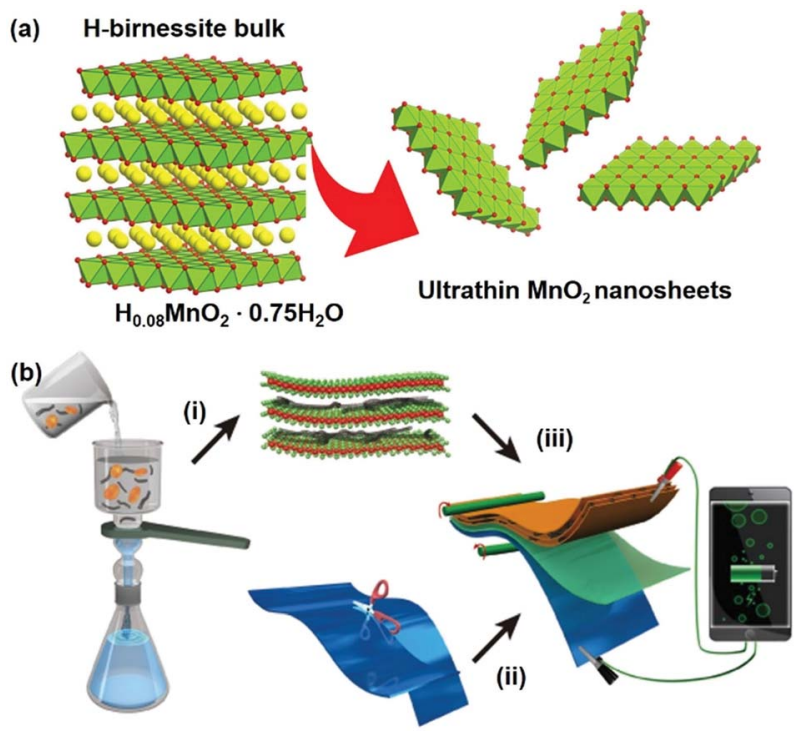

Fig. 1 (a) Crystal structure evolution by liquid exfoliation of the $\mathrm{H}$ birnessite bulk into single-atomic layers. (b) Schematic illustration of (i) the vacuum-assisted filtration strategy to fabricate the freestanding $\mathrm{MnO}_{2} / \mathrm{MWCNT}$ hybrid membrane; (ii) trimmed zinc foil as the anode material; (iii) assembly of a proof-of-concept paper-like ZIB. energy density up to $365 \mathrm{~W} \mathrm{~h} \mathrm{~kg}^{-1}$. We found that $\mathrm{Zn}$ dendrite growth was prevented in the paper-like ZIBs, resulting in superior stability compared with batteries based on a bulk$\mathrm{MnO}_{2}$ cathode. Our design sheds light on developing highperformance ZIBs from two-dimensional nanofluidic channels, and this strategy might be applicable to storage of other metal ions $\left(\mathrm{Na}^{+}, \mathrm{Mg}^{2+}, \mathrm{Ca}^{2+}, \mathrm{Al}^{3+}\right.$, etc. $)$ in next-generation electrochemical energy storage devices. ${ }^{31-34}$

\section{Experimental section}

\subsection{Preparation of the $\mathrm{H}_{0.08} \mathrm{MnO}_{2} \cdot 0.75 \mathrm{H}_{2} \mathrm{O}$ precursor}

Potassium permanganate $\left(\mathrm{KMnO}_{4}, \mathrm{GR}, 6 \mathrm{mmol}\right.$, Sinopharm Chemical Reagent Co. Ltd (SCRC)) was dissolved in $137.5 \mathrm{~mL}$ Milli-Q water $(18.2 \mathrm{M} \Omega \mathrm{cm})$ to form a purple solution, and potassium hydroxide (KOH, AR, $3 \mathrm{~mol}$, SCRC) was added to this solution in two batches under stirring at $400 \mathrm{rpm}$ and then mixed with $20 \mathrm{~mL}$ of a manganese(II) chloride tetrahydrate $\left(\mathrm{MnCl}_{2}\right.$ $\cdot 4 \mathrm{H}_{2} \mathrm{O}, \mathrm{AR}, 0.6 \mathrm{M}, \mathrm{SCRC}$ ) aqueous solution and stirred for $2 \mathrm{~h}$ to obtain a uniform precursor solution. This solution was hydrothermally treated at $175{ }^{\circ} \mathrm{C}$ for 3 days. The manganese oxide precipitate was washed with Milli-Q water 4 times to neutral $\mathrm{pH}$, after which ammonium persulfate $\left(\left(\mathrm{NH}_{4}\right)_{2} \mathrm{~S}_{2} \mathrm{O}_{8}, \mathrm{AR}, 0.25 \mathrm{~mol}\right.$, SCRC) and the neutral solution were added into a three-necked flask at $60{ }^{\circ} \mathrm{C}$ for $3 \mathrm{~h}$ (repeated 3 times) and then filtered and washed with Milli-Q water and finally dried in air at room temperature. The ideal reaction mechanism of the synthesis is:

$$
\mathrm{K}_{0.33} \mathrm{MnO}_{2} \cdot 0.47 \mathrm{H}_{2} \mathrm{O}+\left(\mathrm{NH}_{4}\right)_{2} \mathrm{~S}_{2} \mathrm{O}_{8} \rightarrow \mathrm{H}_{0.08} \mathrm{MnO}_{2} \cdot 0.75 \mathrm{H}_{2} \mathrm{O}
$$

\subsection{Exfoliation}

For the exfoliation process, the as-synthesized $\mathrm{H}_{0.08} \mathrm{MnO}_{2} \cdot 0.75 \mathrm{H}_{2} \mathrm{O}$ $(0.36 \mathrm{~g})$ and tetramethylammonium hydroxide (TMAOH, $10.4 \mathrm{~mL}$, Aladdin) were dispersed into $80 \mathrm{~mL}$ Milli-Q water. The as-obtained suspension was shaken for $24 \mathrm{~h}$ at $100 \mathrm{rpm}$ and washed with Milli$\mathrm{Q}$ water to neutral $\mathrm{pH}$ by the centrifugation (6000 rpm for $10 \mathrm{~min}$ ) method. Subsequently, a further peeling-off process was implemented, in which the as-obtained suspension and tetrabutylammonium hydroxide (TBAOH, $0.74 \mathrm{~mL}$, Aladdin) were dispersed into $90 \mathrm{~mL}$ Milli-Q water and then shaken for $72 \mathrm{~h}$ at $80 \mathrm{rpm}$ to obtain exfoliated $\mathrm{MnO}_{2}$ nanosheets.

\subsection{Preparation of the $\mathrm{MnO}_{2} / \mathrm{MWCNT}$ membrane}

The as-obtained exfoliated $\mathrm{MnO}_{2}$ nanosheet suspension $\left(\sim 40 \mathrm{mmol} \mathrm{L}^{-1}\right)$ was mixed with carbon nanotubes (industrial multi-walled carbon nanotubes (MWCNTs-010-0), Tanfeng Technology Co., Ltd) and an $N$-methylpyrrolidone (NMP, AR, SCRC) solution $\left(0.5 \mathrm{mg} \mathrm{mL} \mathrm{m}^{-1}\right)$ at a volume ratio of $1: 2$ by mechanical grinding for 10 minutes and ultrasonic dispersion for 30 minutes. The $\mathrm{MnO}_{2} / \mathrm{MWCNT}$ membrane was prepared by vacuum filtering the obtained suspension, washing it with MilliQ water 3 times and drying it under ambient conditions for 3 days. The loading mass of MWCNTs on the $\mathrm{MnO}_{2} / \mathrm{MWCNT}$ membrane was around $20 \%$. The mass density of $\mathrm{MnO}_{2}$ / MWCNT electrodes was $\sim 0.96 \mathrm{~g} \mathrm{~cm}^{-3}$. 


\subsection{Preparation of the $\delta$ - $\mathrm{MnO}_{2}$ bulk}

The $\delta-\mathrm{MnO}_{2}$ bulk sample was obtained by heating $\mathrm{KMnO}_{4}$ powder in an air atmosphere at $350{ }^{\circ} \mathrm{C}$ for $5 \mathrm{~h}$ and cooling naturally. The powder product was washed with Milli-Q water 3 times and dried at $80^{\circ} \mathrm{C}$ for $12 \mathrm{~h}$ and finally thoroughly ground. The ZIB cathode made of the $\delta-\mathrm{MnO}_{2}$ bulk was prepared according to the following process: active powder: Ketjen black : poly(vinylidene fluoride) (PVDF) (mass ratio: $7: 2: 1$ ) was mixed homogeneously, and then the slurry mixture was coated onto 304 stainless steel foil and dried under vacuum at $120{ }^{\circ} \mathrm{C}$ for $12 \mathrm{~h}$. Then the stainless steel foil after coating was punched into circular pieces $(d=15 \mathrm{~mm}$, mass density: $1.1 \mathrm{~g} \mathrm{~cm}^{-3}$ ) for the assembly of coin-type cells.

\subsection{Characterization}

The tensile strength of the $\mathrm{MnO}_{2} / \mathrm{MWCNT}$ membrane was measured using an AUTO tensile tester (Labthink, XLW (PC)). A field emission scanning electron microscope (FE-SEM, FEI Nova Nano SEM 450) and an atomic force microscope (AFM, Bruker Dimension Icon) were used to characterize the sample's morphology. X-ray photoelectron spectroscopy (XPS, PerkinElmer PHI 5000C ESCA, with $\mathrm{Mg} \mathrm{K} \alpha$ radiation, standard signal: $\mathrm{C}$ 1s peak $284.6 \mathrm{eV}$ ) analysis was performed to investigate the elemental distribution and chemical components. X-ray powder diffraction (XRD) analysis was performed to investigate the crystal structure (Bruker D8-A25 diffractometer using $\mathrm{Cu} \mathrm{K} \alpha$ radiation $(\lambda=1.5406 \AA)$, the scan rate was $\left.2^{\circ} \mathrm{min}^{-1}\right)$. Thermogravimetric (TG) analysis combined with differential scanning calorimetry (DSC, SDT Q600, the heating rate was $10{ }^{\circ} \mathrm{C} \mathrm{m^{-1 }}$ and the air flow was $50 \mathrm{~mL} \mathrm{~min}^{-1}$ ) was adopted to explore the sample's thermal behavior. Transmission electron microscopy (TEM) and selected area electron diffraction (SAED) were performed using a Philips CM 200 FEG field emission microscope. A zeta-potential tester (Zetasizer Nano ZS90) was used to characterize the surface charge state of the nanosheets dispersed in solvents.

\subsection{Electrochemical measurements}

The electrochemical performances of the assembled coin-type $\mathrm{MnO}_{2} / \mathrm{MWCNTs} / /$ zinc and $\mathrm{MnO}_{2}$ bulk//zinc unit cells, such as the discharge capacity, discharge C-rate capability, and cycling performance, were evaluated using a LAND battery cycle system (Wuhan LAND Electronics Co., LTD, China) in the voltage range of 1.0-1.9 $\mathrm{V}$ under ambient conditions. For the $\mathrm{MnO}_{2} /$ MWCNTs//zinc paper-like battery, the $\mathrm{MnO}_{2} / \mathrm{MWCNT}$ cathode and the high purity zinc foil (thickness of $30 \mu \mathrm{m}$, Tengfeng Metal Materials LTD) were punched into circular pieces $(d=15$ $\mathrm{mm}$ ), Whatman glass fiber (GF, thickness of $350 \mu \mathrm{m}$ ) was used as the separator, and a mixture of zinc sulfate $\left(\mathrm{ZnSO}_{4} \cdot 7 \mathrm{H}_{2} \mathrm{O}\right.$, 99.995\%, $2 \mathrm{M}, \mathrm{SCRC})$ and manganese sulfate $\left(\mathrm{MnSO}_{4} \cdot \mathrm{H}_{2} \mathrm{O}, \mathrm{AR}\right.$, $0.2 \mathrm{M}$, SCRC) aqueous solutions was used as the electrolyte. The charge and discharge cycling performance of the cells was measured at $0.1 \mathrm{~A} \mathrm{~g}^{-1}$ for 600 cycles and the C-rate capability of the cells was examined from $0.1 \mathrm{~A} \mathrm{~g}^{-1}$ to $2 \mathrm{~A} \mathrm{~g}^{-1}$. Cyclic voltammetry (CV) and electrochemical impedance analysis of the
$\mathrm{Zn}^{2+} / \mathrm{Zn}$ unit cells were performed on an electrochemical workstation (CHI660e) over the frequency range of $10 \mathrm{mHz}$ to 1 MHz. The performance (energy and power densities) was estimated based on the weight of the active $\mathrm{MnO}_{2}$ only.

\section{Results and discussion}

Negatively charged $\mathrm{MnO}_{2}$ single-atomic layer nanosheets were prepared by a liquid-exfoliation strategy from the H-birnessite bulk. ${ }^{27}$ A dark-brown colloidal suspension was obtained with a high concentration $\left(\sim 40 \mathrm{mmol} \mathrm{L}^{-1}\right)$ of the $\mathrm{MnO}_{2}$ nanosheets in the water phase (Fig. 2a). Clear Tyndall light scattering of the colloidal suspension was observed in a diluted nanosheet suspension (Fig. 2b). Their negative surface charge was proven by the negative zeta potential measurement $(-32 \mathrm{mV}$, Fig. S1, $\mathrm{ESI} \dagger$ ). Atomic force microscopy (AFM) characterization revealed a typical 2D nanosheet morphology with average lateral dimensions of 1-1.5 $\mu \mathrm{m}$ (Fig. 2c) and a thickness of $1.0 \mathrm{~nm}$ (Fig. 2d and e). Note that the theoretical thickness of the $\mathrm{MnO}_{2}$ single-layer nanosheets is estimated to be $0.52 \mathrm{~nm}$. The measured thickness is slightly larger than the theoretical thickness by approximately $0.4 \mathrm{~nm}$, which might be due to the distance between the substrate and $\mathrm{MnO}_{2}$ as well as between $\mathrm{MnO}_{2}$ and the probe. This phenomenon has been observed in a previous study. ${ }^{30}$ The transmission electron microscope (TEM) image also shows ultrathin sheet-like objects with lateral dimensions similar to those observed in the AFM image (Fig. S2, $\mathrm{ESI} \dagger)$.

The ultrathin nature, nanosheet-like morphology and inherent flexibility are quite promising for constructing freestanding membranes by a facile vacuum-assisted filtration
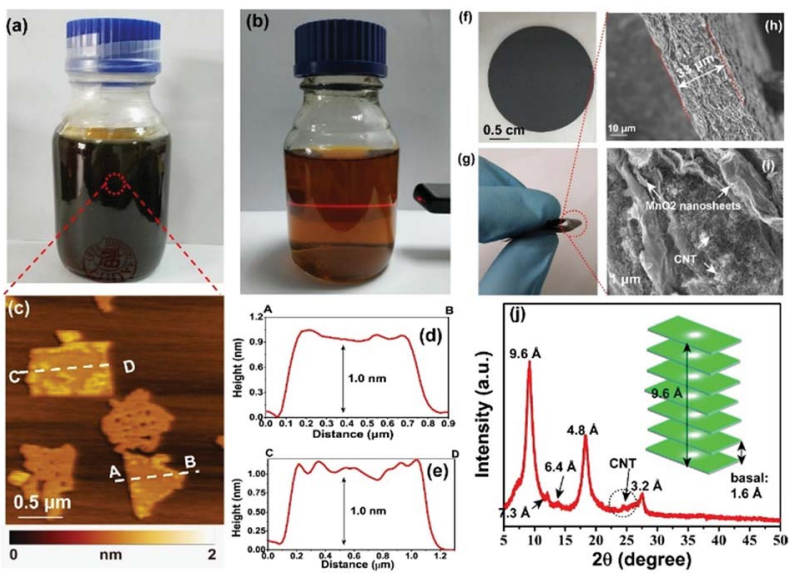

Fig. 2 ( $a$ and b) Photograph of exfoliated $\mathrm{MnO}_{2}$ nanosheets dispersed in Milli-Q water at high and low concentrations, respectively. The Tyndall effect was observed in the diluted solution. (c) Typical AFM image of the $\mathrm{MnO}_{2}$ nanosheets. ( $\mathrm{d}$ and e) The height profile along the dashed line in (d). ( $\mathrm{f}$ and g) The photographs show the $\mathrm{MnO}_{2} / \mathrm{MWCNT}$ membrane with high flexibility. ( $h$ and i) Typical cross-sectional SEM images of the membrane. (j) XRD pattern of the hybrid film. A weak diffraction peak with a $d$-spacing of $7.3 \AA$ was described in Liu's work for aggregated nanosheets centrifuged from the mixture of $\mathrm{H}$-birnessite and $\mathrm{TBAOH} .{ }^{30}$ The characteristic, broad peak of MWCNTs was detected at $2 \theta=26^{\circ}$ 
strategy. In order to improve the electronic conductivity of this membrane, we consider the incorporation of conductive multiwalled carbon nanotubes (MWCNTs) into this membrane sample. Mixing the two colloidal solutions of $\mathrm{MnO}_{2}$ nanosheets and MWCNTs with sonication for an additional $30 \mathrm{~min}$ produces a homogeneous dispersion with no apparent precipitation. Then, a hybrid, black $\mathrm{MnO}_{2} / \mathrm{MWCNT}$ membrane was easily fabricated by the vacuum-assisted filtration strategy with a lateral size of $4 \mathrm{~cm}$ (Fig. 2f). The as-obtained membrane is highly flexible (Fig. 2g), and it can be freely rolled up by hand and using glass rods (Fig. S3, ESI $\dagger$ ). The optimal mass ratio of MWCNTs in the composite $\mathrm{MnO}_{2}$ /MWCNT membrane is $~ 20 \%$ because a high concentration of MWCNTs over this threshold can drastically decrease the flexibility of the hybrid membrane. The top-view SEM image shows a rather smooth and dense surface of our $\mathrm{MnO}_{2}$ /MWCNTs membrane (Fig. S5, ESI $\dagger$ ), which is completely different from the loose, rough structure in the previous work. ${ }^{25}$ The cross-sectional SEM image in Fig. $2 \mathrm{~h}$ suggests that the thickness of this freestanding membrane is $\sim 33 \mu \mathrm{m}$. One can see the densely stacked structure with abundant 2D nanofluidic channels in the cross-section of this membrane (Fig. 2i). X-ray photoelectron spectroscopy (XPS) analysis also confirms the existence of $\mathrm{Mn}, \mathrm{O}$, and $\mathrm{C}$ elements in this hybrid membrane (Fig. S6, ESI $\dagger$ ). The formation of welldefined 2D nanofluidic channels was further confirmed by $\mathrm{X}$ ray diffraction (XRD) characterization (Fig. 2j), which exhibits a series of intense and sharp $(00 l)$ diffraction peaks with a $d$ spacing of $9.6 \AA$, $6.4 \AA$, $4.8 \AA$, and $3.2 \AA$, respectively. This result indicates a basal spacing of $1.6 \AA$ with preferred orientation and ordered stacking along the [010] direction during the vacuumassisted filtration process, and this is well consistent with that of the $\mathrm{MnO}_{2} / \mathrm{MXene}$ hybrid membrane. ${ }^{35}$ The preferred orientation of these restacked nanosheets results in ideal 2D nanofluidic channels with atomically smooth surfaces as highly expected.

The thermal stability of the $\mathrm{MnO}_{2} / \mathrm{MWCNT}$ membrane was further evaluated by thermogravimetric analysis (TGA), which showed that our $\mathrm{MnO}_{2} / \mathrm{MWCNT}$ membrane was thermally stable up to $225{ }^{\circ} \mathrm{C}$ (Fig. S7, ESI $\dagger$ ). We further checked the wettability of our $\mathrm{MnO}_{2} / \mathrm{MWCNT}$ membrane in the as-employed $2 \mathrm{M} \mathrm{ZnSO}_{4} / 0.2 \mathrm{M} \mathrm{MnSO}_{4}$ aqueous electrolyte for ZIB applications. This $\mathrm{MnO}_{2} / \mathrm{MWCNT}$ membrane is hydrophilic with an initial contact angle of $18.7^{\circ}$, and this contact angle gradually decreased to $5.2^{\circ}$ in a short time of $\sim 15$ seconds (Fig. S8, ESI $\dagger$ ). The rapid decrease in contact angle may provide evidence of the facile permeation and transfer of the aqueous electrolyte in our $\mathrm{MnO}_{2} /$ MWCNT membrane. ${ }^{36}$

Based on the successful formation of $2 \mathrm{D}$ nanofluidic channels, the electrochemical properties of the $\mathrm{MnO}_{2} / \mathrm{MWCNT}$ membrane cathode were subsequently measured in a typical coin-type cell. Fig. 3 a shows the $\mathrm{CV}$ profile of the $\mathrm{MnO}_{2} / \mathrm{MWCNT}$ membrane cathode at $0.05 \mathrm{mV} \mathrm{s}^{-1}$, and two redox peaks at $1.42 \mathrm{~V}$ and $1.30 \mathrm{~V}$ were detected. Fig. $3 \mathrm{~b}$ shows the cyclic voltammograms (CVs) of this membrane sample in an aqueous $2 \mathrm{M} \mathrm{ZnSO}_{4} / 0.2 \mathrm{M} \mathrm{MnSO}_{4}$ electrolyte within the coin-type cell. Our CV curves are mostly consistent with those of the $\delta-\mathrm{MnO}_{2}$ bulk electrode in the previous study. ${ }^{37}$ Two cathodic peaks
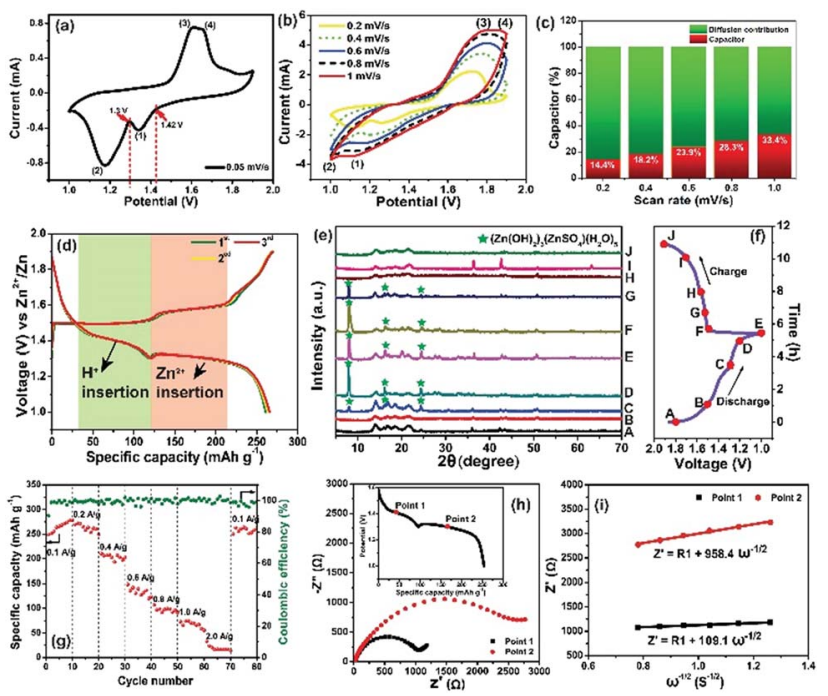

Fig. 3 (a) $\mathrm{CV}$ profile of the $\mathrm{MnO}_{2} / \mathrm{MWCNT}$ membrane cathode at a slow scanning rate of $0.05 \mathrm{mV} \mathrm{s}^{-1}$. (b) $\mathrm{CV}$ profile of the $\mathrm{MnO}_{2}$ / MWCNT membrane cathode at $0.2-1.0 \mathrm{mV} \mathrm{s}^{-1}$. (c) The capacitive contribution (red region) to the total current at various scan rates. (d) Characteristic galvanostatic charge/discharge profile of the $\mathrm{MnO}_{2}$ / MWCNTs in the initial cycles. (e and f) Ex situ XRD pattern of the $\delta$ $\mathrm{MnO}_{2} / \mathrm{MWCNT}$ cathode at various discharge/charge states. (g) Rate capability. (h) Nyquist spectrum measured at the corresponding point on the discharge curve (inset) for $\mathrm{Zn}^{2+}$ diffusion coefficient analysis. (i) $Z^{\prime}$ vs. $\omega^{-1 / 2}$ plots in the low frequency region obtained from the electrochemical impedance spectroscopy measurements.

located at $1.35 \mathrm{eV}$ and $1.17 \mathrm{eV}$ can be observed, which are attributed to $\mathrm{Zn}^{2+}$ insertion into the restacked $\delta-\mathrm{MnO}_{2}$ nanosheets and the consequent reduction of $\mathrm{Mn}^{4+}$ to lower oxidation states, respectively. The appearance of an overlapped anodic peak at around $1.70 \mathrm{~V}$ may correspond to $\mathrm{Zn}$-extraction which is accompanied by the recovery to the Mn(Iv) state. We further estimate the pseudocapacitance-like contribution by clarifying the kinetics to separate the capacitive-controlled and diffusioncontrolled capacities. In general, the capacitive contribution can be quantified using the modified power law: ${ }^{38}$

$$
I=I_{\text {capacitive }}+I_{\text {diffusion }}=k_{1} \nu+k_{2} \nu^{1 / 2}
$$

where $I$ is the current; $\nu$ is the scan rate; $k_{1} \nu$ and $k_{2} \nu^{1 / 2}$ correspond to the current contributions from the pseudocapacitive effect and diffusion-controlled insertion, respectively (Fig. S10, $\mathrm{ESI} \dagger)$. The typical CV profile in Fig. 3b separates the capacitive current (red region) from the diffusion current (green region). The contribution of capacitive current is $14.4 \%, 18.2 \%, 23.9 \%$, $28.3 \%$ and $33.4 \%$ at scan rates of $0.2,0.4,0.6,0.8$ and $1.0 \mathrm{mV} \mathrm{s}^{-1}$ (Fig. 3c), respectively. Fig. 3d depicts the characteristic galvanostatic charge/discharge profile of the $\mathrm{MnO}_{2} / \mathrm{MWCNT}$ membrane electrode in the initial three cycles. Two discharge plateaus at $1.42 \mathrm{~V}$ and $1.30 \mathrm{~V}$ should be ascribed to $\mathrm{H}^{+}$and $\mathrm{Zn}^{2+}$ insertion and extraction, respectively. In general, these two discharge plateaus were easily observed in manganese oxidebased ZIBs due to the coexistence of the reversible $\mathrm{Zn}$ ion insertion/extraction and proton reaction during the electrochemical process as follows: ${ }^{39}$ 


$$
\mathrm{MnO}_{2}+x \mathrm{Zn}^{2+}+2 x \mathrm{e}^{-} \leftrightarrow \mathrm{Zn}_{x} \mathrm{MnO}_{2} \cdot x \mathrm{H}_{2} \mathrm{O},(0<x<1)
$$
( $\mathrm{Zn}$ ion insertion/extraction)

$$
\begin{gathered}
\mathrm{MnO}_{2}+\mathrm{H}^{+}+\mathrm{e}^{-} \leftrightarrow \mathrm{MnOOH} \text { (proton reaction) } \\
4 \mathrm{Zn}^{2+}+6 \mathrm{OH}^{-}+\mathrm{SO}_{4}{ }^{2-}+5 \mathrm{H}_{2} \mathrm{O} \leftrightarrow 3 \mathrm{Zn}(\mathrm{OH})_{2} \cdot \mathrm{ZnSO}_{4} \cdot 5 \mathrm{H}_{2} \mathrm{O}
\end{gathered}
$$

To further understand the phase evolution more clearly, ex situ XRD characterization of this freestanding membrane was performed as shown in Fig. 3e and f. Notably, the XRD pattern at the initial discharging state (A) was drastically different from that of the fresh $\mathrm{MnO}_{2} / \mathrm{MWCNT}$ membrane just after vacuum filtration (Fig. 2n), which was also reported by T. Vaughey. ${ }^{40}$ During the following discharging process $(\mathrm{A} \rightarrow \mathrm{E})$, the diffraction peaks significantly decreased in intensity, and some sharp peaks (including sharp peaks at $7.9^{\circ}, 16.2^{\circ}$, and $24.2^{\circ}$ and other weak peaks highlighted by grey cycles) emerged when it was discharged to $1.3 \mathrm{~V}$, which can be indexed to $3 \mathrm{Zn}(\mathrm{OH})_{2}$ $\cdot \mathrm{ZnSO}_{4} \cdot 5 \mathrm{H}_{2} \mathrm{O}$ (zinc hydroxide sulfate hydrate, JCPDS 78-0246). ${ }^{39}$ The formation of zinc hydroxide sulfate hydrate should be attributed to the increasing amount of $\mathrm{OH}^{-}$groups in the electrolyte, further confirming the reversible proton reaction. ${ }^{\mathbf{1 1}}$ During the subsequent charging process $(\mathrm{E} \rightarrow \mathrm{J})$, the diffraction peaks from the intermediate phase of zinc hydroxide sulfate hydrate gradually disappeared, and the pattern finally well recovered to the initial state (A) when the charge voltage was $1.6 \mathrm{~V}(\mathrm{H})$. In general, the ex situ XRD characterization clearly confirms the excellent reversibility of the $\mathrm{Zn}^{2+}$ intercalation/ deintercalation process in our $\mathrm{MnO}_{2} / \mathrm{MWCNT}$ membrane. The rate capability of the $\mathrm{MnO}_{2} / \mathrm{MWCNT}$ electrode in the range of 1$1.9 \mathrm{~V}$ is evaluated at various current densities $\left(0.1-2 \mathrm{~A} \mathrm{~g}^{-1}\right)$ (Fig. 3g). The $\mathrm{MnO}_{2} / \mathrm{MWCNT}$ electrode shows high reversible capacities of $273.8,265.1,206.8,135.5,99,71.4$ and $20.3 \mathrm{~mA} \mathrm{~h} \mathrm{~g}^{-1}$ at current densities of $0.1,0.2,0.4,0.6,0.8,1$ and $2 \mathrm{~A} \mathrm{~g}^{-1}$, respectively (Fig. S11, ESI $\dagger$ ). When the current density is decreased back to $0.1 \mathrm{~A} \mathrm{~g}^{-1}$, the capacity returns to $270.2 \mathrm{~mA} \mathrm{~h} \mathrm{~g}^{-1}$, demonstrating its outstanding capacity retention at both low and high rates.

It has been revealed that the electrolyte ions show drastically different behavior when confined in 2D nanochannels. ${ }^{22-24}$ Subsequently, the $\mathrm{Zn}^{2+}$ diffusion ability in our $\delta-\mathrm{MnO}_{2} / \mathrm{MWCNT}$ membrane was identified using electrochemical impedance spectroscopy (EIS). Combining the Nyquist spectra measured at the first (Point 1) and second (Point 2) discharge depth (Fig. 3h) and $Z^{\prime}$ vs. $\omega^{-1 / 2}$ plots (Fig. 3i), the diffusion coefficient can be calculated based on the following equation: ${ }^{42,43}$

$$
D=\frac{R^{2} T^{2}}{2 A^{2} n^{4} F^{4} C^{2} \sigma^{2}}
$$

where $R, T$, and $F$ are the gas constant $\left(8.314 \mathrm{~J} \mathrm{~K}^{-1} \mathrm{~mol}^{-1}\right)$, the experimental temperature $(298 \mathrm{~K})$, and the Faraday constant (96, $\left.500 \mathrm{C} \mathrm{mol}^{-1}\right)$, respectively. $A$ is the surface area of the electrode, $n$ is the number of electrons per molecule taking part in the electronic transfer reaction, $C$ is the concentration of inserted ions in $\mathrm{MnO}_{2} /$ MWCNTs, and $\sigma$ is the slope of the line $Z^{\prime}$ vs. $\omega^{-1 / 2}$. The calculated diffusion coefficients of the proton $\left(\mathrm{H}^{+}\right)$ and $\mathrm{Zn}$-ion platform are as high as $1.49 \times 10^{-12}$ (the first discharge platform) and $1.93 \times 10^{-14} \mathrm{~cm}^{2} \mathrm{~s}^{-1}$ (the second platform), respectively, which are comparable with the highest values in the recent reports on $\mathrm{MnO}_{2}$ cathodes for ZIBs. ${ }^{32}$ As a comparison, the $\delta-\mathrm{MnO}_{2}$ bulk with irregular morphology was prepared via thermal decomposition of $\mathrm{KMnO}_{4}$ similarly to Kim's route ${ }^{30}$ (Fig. S12, ESI $\dagger$ ). The $\mathrm{MnO}_{2}$ bulk sample shows smaller values of proton and $\mathrm{Zn}$-ion diffusion coefficients of $3.63 \times 10^{-13}$ and $1.56 \times 10^{-14} \mathrm{~cm}^{2} \mathrm{~s}^{-1}$, respectively (Fig. S13, ESI $\dagger$ ). Such a high $\mathrm{Zn}^{2+}$ diffusion coefficient should be attributed to the advantages of our $2 \mathrm{D} \delta-\mathrm{MnO}_{2}$ nanofluidic channels: (i) the incorporated MWCNTs (as both the spacer and the conductive enhancer) play a crucial role in the fast charge diffusion kinetics due to their highly disordered porous structure, and the channels in the vertical direction were crosslinked with the incorporated MWCNTs for enhanced $\mathrm{Zn}$ ion migration; (ii) the $\mathrm{MnO}_{2}$ nanosheets exfoliated from the $\mathrm{H}_{0.08^{-}}$ $\mathrm{MnO}_{2} \cdot 0.75 \mathrm{H}_{2} \mathrm{O}$ bulk generally show a strongly negatively charged surface, and our $\mathrm{MnO}_{2}$ nanofluidic channels contain abundant horizontal and vertical pathways for $\mathrm{Zn}^{2+}$ transport. We theoretically compare the Debye length of $\mathrm{Zn}^{2+}$ with the interlayer spacing of the horizontal pathway. In principle, the value of the Debye length $\left(\lambda_{\mathrm{D}}\right)$ can be calculated using: ${ }^{\mathbf{4 4}}$

$$
\lambda_{\mathrm{D}}=\frac{3.04 \times 10^{-10}}{z_{\mathrm{i}} \sqrt{c_{\mathrm{i}}}}
$$

where $z_{\mathrm{i}}$ and $c_{\mathrm{i}}$ are the valency and concentration of $\mathrm{Zn}^{2+}$, respectively. In our work, a $2 \mathrm{M} \mathrm{ZnSO}_{4} / 0.2 \mathrm{M} \mathrm{MnSO}_{4}$ aqueous solution was employed as the electrolyte. Thus, the Debye length is estimated to be $0.11 \mathrm{~nm}$. Note that the $d$-spacing (0.96 $\mathrm{nm}$ ) of restacked $\delta-\mathrm{MnO}_{2}$ nanofluidic channels determined from the XRD pattern (Fig. 2n) is larger than the value of the Debye length, showing the same tendency as the $\mathrm{Co}_{3} \mathrm{O}_{4}$ nanochannels in Li ion storage reported by $\mathrm{Yu}$ et al. ${ }^{23}$ Accordingly, inside our 2D nanochannel, when the characteristic dimensions are comparable or less than the $\mathrm{Zn}^{2+}$ Debye length $(0.11$ $\mathrm{nm}$ ), the negative $\mathrm{MnO}_{2}$ surface charges on the inner walls would repel counterions of the same charge (negative $\mathrm{SO}_{4}{ }^{2-}$ groups), making $\mathrm{Zn}^{2+}$ the dominating charge carriers. ${ }^{25,45}$ This unipolar ionic transport is generally beneficial for high $\mathrm{Zn}^{2+}$ conductivity and a high diffusion coefficient..$^{22,23}$

More attention has been paid to the long-term cycle performance of this $\mathrm{MnO}_{2} / \mathrm{MWCNT}$ membrane. Our $\delta-\mathrm{MnO}_{2}$ membrane-like cathode delivers a capacity of $273.8 \mathrm{~mA} \mathrm{~h} \mathrm{~g}^{-1}$ for 600 cycles with a coulombic efficiency around $100 \%$. In contrast, the $\delta-\mathrm{MnO}_{2}$ bulk counterpart displays rather poor cycling stability, the capacity of which drastically faded after the initial 10 cycles (Fig. $4 \mathrm{a}$ and S14, ESI $\dagger$ ). In general, the formation of needle-like $\mathrm{Zn}$ dendrites on the $\mathrm{Zn}$ anode should be the main reason for the rapid degradation of capacity and poor stability. ${ }^{7}$ Thus, the reason for the difference in stability of our $\mathrm{MnO}_{2}$ / MWCNT membrane was further studied by SEM observation of the $\mathrm{Zn}$ foil anode after long-term cycling. Interestingly, one can clearly see that the $\mathrm{Zn}$ foil taken from the $\delta-\mathrm{MnO}_{2}$ bulk ZIBs shows a rough surface with dense $\mathrm{Zn}$ dendrites (Fig. 4b). However, the $\delta-\mathrm{MnO}_{2} / \mathrm{MWCNT}$ membrane based ZIBs show a typical dendrite-free surface (Fig. 4c) with the absence of any $\mathrm{ZnO}$ by-products on the $\mathrm{Zn}$ foil after 600 charge/discharge cycles 

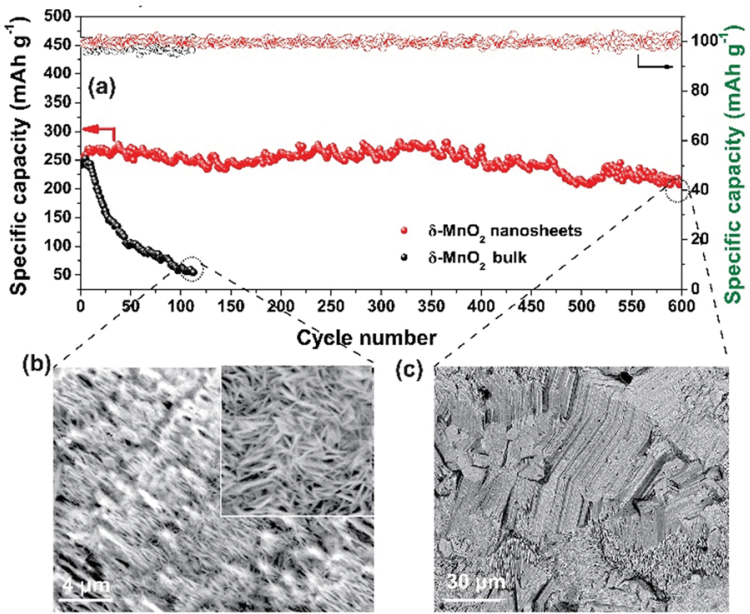$$
\text { (d) }
$$
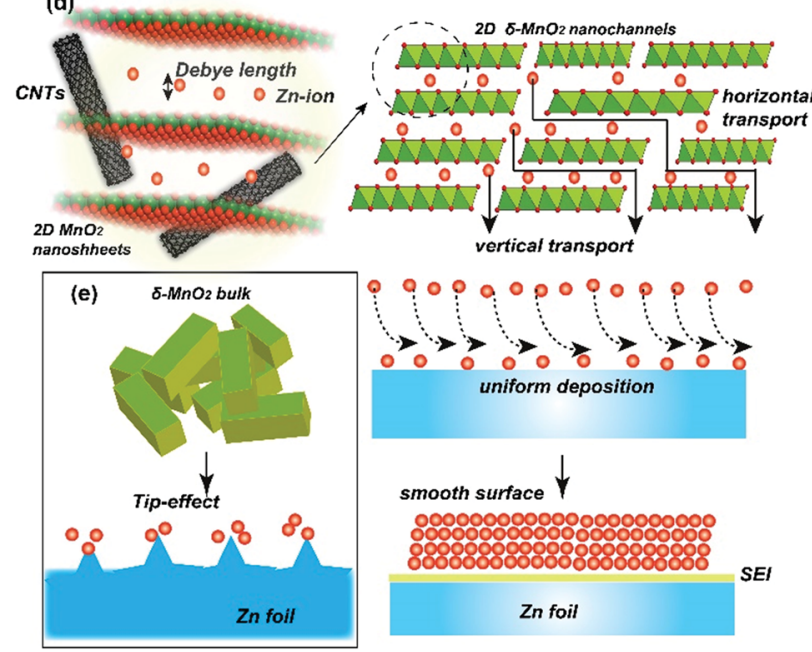

Fig. 4 (a) Cycle performance and coulombic efficiency of the $\mathrm{MnO}_{2}$ based $\mathrm{ZIBs}$ in a voltage range of $1.0-1.9 \mathrm{~V}$ at $0.1 \mathrm{~A} \mathrm{~g}^{-1}$. SEM images of the $\mathrm{Zn}$ foil anode surface morphology in the (b) $\delta-\mathrm{MnO}_{2}$ bulk and (c) flexible $\mathrm{MnO}_{2} /$ MWCNT ZIBs after 600 cycles. Schematic illustration of the $\mathrm{Zn}^{2+}$ transport process in (d) 2D nanofluidic channels and (e) the $\delta$ $\mathrm{MnO}_{2}$ bulk, respectively.

(Fig. S15, ESI $\dagger$ ). Although the origin of the dendrite-free characteristics in the membrane-based battery is not yet clear, we speculate that the smooth surface in our advanced 2D channel structure may be responsible. Recently, Liaw et al. found that the inhomogeneity of the distribution of the current density increases with the increase of the cathode particle size and surface roughness. ${ }^{12}$ In our case, taking advantage of the characteristic 2D planar morphology with a high aspect ratio, the nanosheets are generally tiled on the filter paper during the vacuum filtration process. As a result, there are almost no MWCNTs on the outermost surface of the $\mathrm{MnO}_{2} / \mathrm{MWCNT}$ membrane (Fig. 2i and S5 $\dagger$ ). Such a smooth surface of the $\mathrm{MnO}_{2} / \mathrm{MWCNT}$ membrane cathode could significantly reduce the concentration gradient in the electrolyte and induce homogeneous $\mathrm{Zn}^{2+}$ stripping/plating on the zinc anode (Fig. 4d). In contrast, for the bulk $\mathrm{MnO}_{2}$ cathode, the sharp corners and irregular morphology of the bulk $\mathrm{MnO}_{2}$ gives rise to the tip-effect with a high concentration gradient during the $\mathrm{Zn}^{2+}$ stripping/plating process (Fig. 4e). Finally, dense Zn dendrite growth occurred at the surface of the $\mathrm{Zn}$ foil, drastically decreasing the cycling stability of the battery system. ${ }^{7-9}$

We finally assembled a sandwiched, paper-like ZIB using the $\delta$ - $\mathrm{MnO}_{2}$ membrane, a $2 \mathrm{~mol} \mathrm{~L}{ }^{-1} \mathrm{ZnSO}_{4}+0.2 \mathrm{~mol} \mathrm{~L}^{-1} \mathrm{MnSO}_{4}$ solution, PET non-woven fabric (thickness $\sim 80 \mu \mathrm{m}$ ) and flexible $\mathrm{Zn}$ foil as the cathode, electrolyte, separator and anode, respectively (Fig. 5a). This paper-like battery shows a thickness of just $\sim 132 \mu \mathrm{m}$ (Fig. 5b) which is comparable with that of standard A4 printing paper (Fig. 5c). Two paper batteries connected in series were able to light up a red light-emitting diode (LED) indicator (Fig. 5d). The flexibility of this battery was tested by bending this device at various angles from $45^{\circ}$ to $180^{\circ}$, while well maintaining the same energy storage characteristics as those in the initial state (Fig. 5d-i, ESI Video $1 \dagger$ ). Compared to a single paper-like ZIB with a charge/discharge potential of $1.4 \mathrm{~V}$, two ZIBs connected in series can achieve $2.8 \mathrm{~V}$ in a similar charge/discharge time (Fig. 5j). The flexible ZIB delivers a capacity of $181.6 \mathrm{~mA} \mathrm{~h} \mathrm{~g}{ }^{-1}$ for 630 cycles at $0.5 \mathrm{~A} \mathrm{~g}^{-1}$ (Fig. S16 $\dagger$ ). The energy density and power density are $365 \mathrm{~W} \mathrm{~h} \mathrm{~kg}^{-1}$ and $105 \mathrm{~W} \mathrm{~kg}^{-1}$ (estimated based on the weight of the active $\mathrm{MnO}_{2}$ only), respectively. Such a high energy density surpasses not only that of recently reported $\mathrm{MnO}_{2}$-based ZIBs, but also that of other V-based and HCF-based counterparts (Fig. 5k). ${ }^{3741,46-53}$
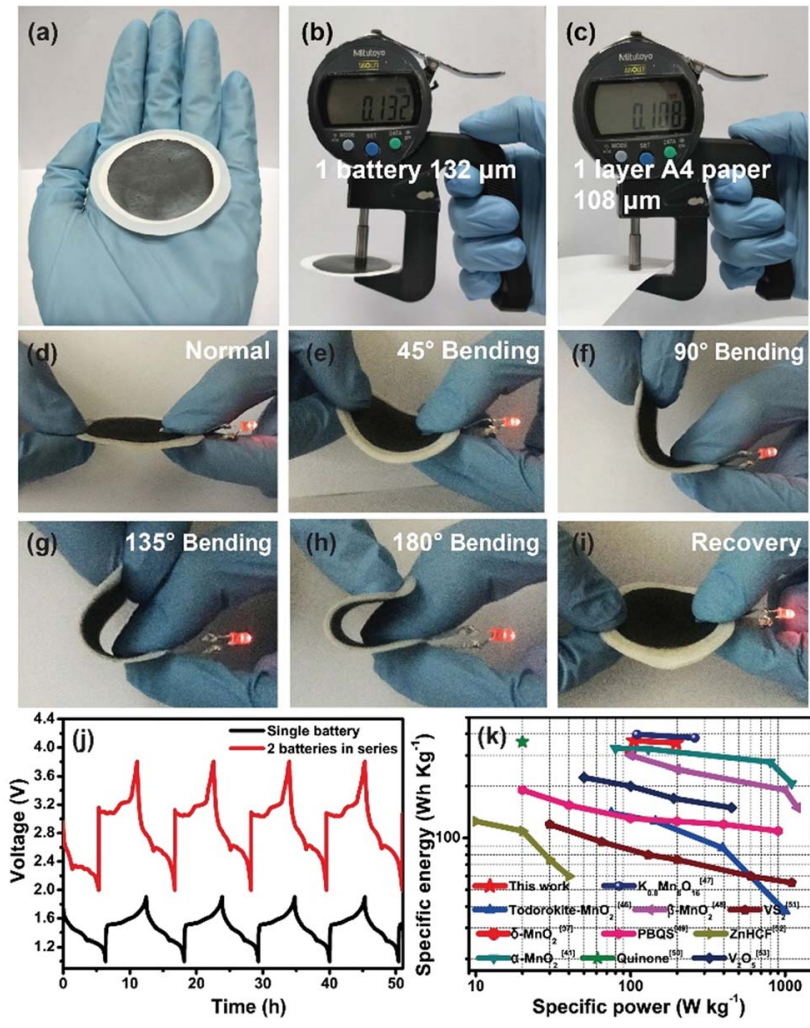

Fig. 5 (a) Photograph of the as-assembled paper-like ZIBs. Comparison between the thickness of (b) the membrane-like ZIBs and (c) standard A4 printing paper. (d-i) The flexible membrane-battery powers a red LED indicator at various bending angles. (j) Galvanostatic charge/discharge curves of a single battery and two batteries connected in series at $0.05 \mathrm{~A} \mathrm{~g}^{-1}$. ( $\mathrm{k}$ ) Ragone plot related to energy and power densities of recently reported ZIBs and the present work. 


\section{Conclusions}

In summary, we have successfully constructed $2 \mathrm{D} \mathrm{MnO}_{2}$ nanofluidic channels by the restacking of abundant single-layer $\delta$ $\mathrm{MnO}_{2}$ nanosheets. Compared to the $\delta-\mathrm{MnO}_{2}$ bulk, our $2 \mathrm{D} \mathrm{MnO}_{2}$ nanofluidic channels show fast $\mathrm{Zn}^{2+}$ transport and superior cycling stability. The high-performance of $\mathrm{Zn}^{2+}$ storage in our rationally designed nanofluidic channels should be associated with the following merits: (1) 2D nanochannels provide abundant interconnected ion transport pathways in vertical and horizontal directions to make the $\mathrm{Zn}^{2+}$ flow uniform, preventing the tip-effect and dendrite formation during $\mathrm{Zn}$ ion deposition. (2) The implantable MWCNTs play a crucial role in the fast charge diffusion kinetics due to their highly disordered porous structure, and the channels in the vertical direction were crosslinked with the implantable MWCNTs for enhanced $\mathrm{Zn}$ ion migration. (3) The void space inside the nanofluidic channels may effectively alleviate structural stress and buffer the volume change during the $\mathrm{Zn}^{2+}$ insertion/extraction, avoiding the rapid decay of specific capacity of the ZIBs during cycling caused by irreversible structural collapse of the cathode. (4) Our freestanding $\delta-\mathrm{MnO}_{2} / \mathrm{MWCNT}$ membrane does not contain any polymer or insulating binder which will avoid sacrificing the active substance content in the ZIBs, thereby achieving enhanced specific capacity after normalization when compared to the conventional $\delta-\mathrm{MnO}_{2}$ bulk electrodes. Our design sheds light on developing high-performance ZIBs from twodimensional nanofluidic channels, and this strategy might be applicable to storage of other metal ions $\left(\mathrm{Mg}^{2+}, \mathrm{Ca}^{2+}, \mathrm{Al}^{3+}\right.$, etc. $)$ in next-generation electrochemical energy storage devices.

\section{Conflicts of interest}

There are no conflicts to declare.

\section{Acknowledgements}

This work was financially supported by the Research Program of State Grid Corporation of China (GYW17201800011).

\section{References}

1 E. Hu and X.-Q. Yang, Nat. Mater., 2018, 17, 480.

2 G. Fang, J. Zhou, A. Pan and S. Liang, ACS Energy Lett., 2018, 3, 2480.

3 L. Ma, S. Chen, H. Li, Z. Ruan, Z. Tang, Z. Liu, Z. Wang, Y. Huang, Z. Pei, J. A. Zapien and C. Zhi, Energy Environ. Sci., 2018, 11, 2521.

4 H. Li, C. Han, Y. Huang, Y. Huang, M. Zhu, Z. Pei, Q. Xue, Z. Wang, Z. Liu, Z. Tang, Y. Wang, F. Kang, B. Li and C. Zhi, Energy Environ. Sci., 2018, 11, 941.

5 S. Guo, G. Fang, S. Liang, M. Chen, X. Wu and J. Zhou, Acta Mater., 2019, 180, 51.

6 F. Liu, Z. Chen, G. Fang, Z. Wang, Y. Cai, B. Tang, J. Zhou and S. J. N.-M. L. Liang, Nano-Micro Lett., 2019, 11, 25.

7 D. Lin, Y. Liu and Y. Cui, Nat. Nanotechnol., 2017, 12, 194.
8 Z. Xing, S. Wang, A. Yu and Z. Chen, Nano Energy, 2018, 50, 229.

9 J.-l. Ma, F.-l. Meng, Y. Yu, D.-p. Liu, J.-m. Yan, Y. Zhang, X.-b. Zhang and Q. Jiang, Nat. Chem., 2019, 11, 64.

10 F. Wu, Y.-X. Yuan, X.-B. Cheng, Y. Bai, Y. Li, C. Wu and Q. Zhang, Energy Storage Materials, 2018, 15, 148.

11 L. Li, S. Li and Y. Lu, Chem. Commun., 2018, 54, 6648.

12 A. W. Abboud, E. J. Dufek and B. Liaw, J. Electrochem. Soc., 2019, 166, A667.

13 W. Lu, C. Xie, H. Zhang and X. Li, ChemSusChem, 2018, 11, 3996.

14 D. Kundu, B. D. Adams, V. Duffort, S. H. Vajargah and L. F. Nazar, Nat. Energy, 2016, 1, 16119.

15 H. Pan, Y. Shao, P. Yan, Y. Cheng, K. S. Han, Z. Nie, C. Wang, J. Yang, X. Li, P. Bhattacharya, K. T. Mueller and J. Liu, Nat. Energy, 2016, 1, 16039.

16 P. Yu, Y. Zeng, H. Zhang, M. Yu, Y. Tong and X. Lu, Small, 2019, 15, 1804760.

17 F. Wang, O. Borodin, T. Gao, X. Fan, W. Sun, F. Han, A. Faraone, J. A. Dura, K. Xu and C. Wang, Nat. Mater., 2018, 17, 543.

18 M. Chhowalla, H. S. Shin, G. Eda, L.-J. Li, K. P. Loh and H. Zhang, Nat. Chem., 2013, 5, 263.

19 A. K. Geim and I. V. Grigorieva, Nature, 2013, 499, 419.

20 F. Xia, H. Wang, D. Xiao, M. Dubey and A. Ramasubramaniam, Nat. Photonics, 2014, 8, 899.

21 K. Chen and L. Li, Adv. Mater., 2019, 31, 1901115.

22 Z. Deng, H. Jiang and C. Li, Small, 2018, 14, 1800148.

23 Y. Zhu, L. Peng, Z. Fang, C. Yan, X. Zhang and G. Yu, Adv. Mater., 2018, 30, 1706347.

24 J. Zhao, G. Zhou, K. Yan, J. Xie, Y. Li, L. Liao, Y. Jin, K. Liu, P.-C. Hsu, J. Wang, H.-M. Cheng and Y. Cui, Nat. Nanotechnol., 2017, 12, 993.

25 K. Raidongia and J. Huang, J. Am. Chem. Soc., 2012, 134, 16528.

26 A. R. Koltonow and J. Huang, Science, 2016, 351, 6280.

27 C. Yan, C. Lv, Y. Zhu, G. Chen, J. Sun and G. Yu, Adv. Mater., 2017, 29, 1703909.

28 Y. Huang, J. Liu, Q. Huang, Z. Zheng, P. Hiralal, F. Zheng, D. Ozgit, S. Su, S. Chen, P.-H. Tan, S. Zhang and H. Zhou, npj Flex. Electron., 2018, 2, 21.

29 Y. Omomo, T. Sasaki, J. Wang and M. Watanabe, J. Am. Chem. Soc., 2003, 125, 3568.

30 Z. Liu, R. Ma, Y. Ebina, K. Takada and T. Sasaki, Chem. Mater., 2007, 19, 6504.

31 B. Xu, S. Qi, P. He and J. Ma, Chem.-Asian J., 2019, 14, 2925. 32 X. Xie, M. Mao, S. Qi and J. Ma, CrystEngComm, 2019, 21, 3755.

33 C. Cui, H. Wang, M. Wang, X. Ou, Z. Wei, J. Ma and Y. Tang, Small, 2019, 15, 1902659.

34 M. Wu, W. Ni, J. Hu and J. Ma, Nano-Micro Lett., 2019, 11, 44. 35 W. Liu, Z. Wang, Y. Su, Q. Li, Z. Zhao and F. Geng, Adv. Energy Mater., 2017, 7, 1602834.

36 S. F. Li, C. Yu, J. Yang, C. T. Zhao, M. D. Zhang, H. W. Huang, Z. B. Liu, W. Guo and J. S. Qiu, Energy Environ. Sci., 2017, 10, 1958. 
37 M. H. Alfaruqi, J. Gim, S. Kim, J. Song, D. T. Pham, J. Jo, Z. Xiu, V. Mathew and J. Kim, Electrochem. Commun., 2015, 60, 121.

38 Y. Yan, B. Hao, D. Wang, G. Chen, E. Markweg, A. Albrecht and P. Schaaf, J. Mater. Chem. A, 2013, 1, 14507.

39 D. Chao, W. Zhou, C. Ye, Q. Zhang, Y. Chen, L. Gu, K. Davey and S.-Z. Qiao, Angew. Chem., Int. Ed., 2019, 58, 7823.

40 S.-D. Han, S. Kim, D. Li, V. Petkov, H. D. Yoo, P. J. Phillips, H. Wang, J. J. Kim, K. L. More, B. Key, R. F. Klie, J. Cabana, V. R. Stamenkovic, T. T. Fister, N. M. Markovic, A. K. Burrell, S. Tepavcevic and J. T. Vaughey, Chem. Mater., 2017, 29, 4874.

41 H. Pan, Y. Shao, P. Yan, Y. Cheng, K. S. Han, Z. Nie, C. Wang, J. Yang, X. Li, P. Bhattacharya, K. T. Mueller and J. Liu, Nat. Energy, 2016, 1, 16039.

42 Y. Liu, Y. Zhou, J. Zhang, S. Zhang and P. Ren, J. Power Sources, 2016, 314, 1.

43 H. Liu, C. Li, H. P. Zhang, L. J. Fu, Y. P. Wu and H. Q. Wu, J. Power Sources, 2006, 159, 717.

44 R. B. Schoch, J. Han and P. Renaud, Rev. Mod. Phys., 2008, 80, 839.
45 D. Stein, M. Kruithof and C. Dekker, Phys. Rev. Lett., 2004, 93, 035901.

46 J. Lee, J. B. Ju, W. I. Cho, B. W. Cho and S. H. Oh, Electrochim. Acta, 2013, 112, 138.

47 G. Fang, C. Zhu, M. Chen, J. Zhou, B. Tang, X. Cao, X. Zheng, A. Pan and S. Liang, Adv. Funct. Mater., 2019, 29, 1808375.

48 N. Zhang, F. Cheng, J. Liu, L. Wang, X. Long, X. Liu, F. Li and J. Chen, Nat. Commun., 2017, 8, 405.

49 G. Dawut, Y. Lu, L. Miao and J. Chen, Inorg. Chem. Front., 2018, 5, 1391.

50 Q. Zhao, W. Huang, Z. Luo, L. Liu, Y. Lu, Y. Li, L. Li, J. Hu, H. Ma and J. Chen, Sci. Adv., 2018, 4, eaao1761.

51 P. He, M. Yan, G. Zhang, R. Sun, L. Chen, Q. An and L. Mai, Adv. Energy Mater., 2017, 7, 1601920.

52 L. Zhang, L. Chen, X. Zhou and Z. Liu, Adv. Energy Mater., 2015, 5, 1400930.

53 P. Hu, M. Yan, T. Zhu, X. Wang, X. Wei, J. Li, L. Zhou, Z. Li, L. Chen and L. Mai, ACS Appl. Mater. Interfaces, 2017, 9, 42717. 